OECDpublishing

\title{
THE ROLE OF CHINA'S FEED DEFICIT IN INTERNATIONAL GRAIN MARKETS
}

OECD FOOD, AGRICULTURE AND FISHERIES PAPER

January $2022 \quad \mathbf{n}^{\circ} \mathbf{1 7 2}$ 


\title{
OECD TRADE AND AGRICULTURE DIRECTORATE
}

\section{The Role of China's Feed Deficit in International Grain Markets}

\author{
Marcel Adenäuer
}

International grain prices experienced a sharp increase during the 2020/2021 marketing season, most likely due to the unprecedented increase of imported grains by China. What would be the possible impact on international grain markets if China remains a strong grain importer? The scenario developed to explore the impact of such a development shows that further increases in Chinese grain imports over the medium term could result in a $4 \%$ to $25 \%$ increase in agriculture commodity prices compared to what was projected in the OECD-FAO Agricultural Outlook 2021-2030.

Keywords: Food price inflation, food security, commodity markets, cereal trade, African Swine Fever JEL codes: C61, F17, Q11, Q17

\section{Acknowledgements}

The author is grateful to Koen Deconinck, Hubertus Gay, Lee Ann Jackson, Clara Frezal, Martin von Lampe (OECD), Shawn Arita (USDA), and Erin Collier (FAO) for their review and valuable comments, and to Michèle Patterson for preparing this report for publication. The author also wishes to thank the members of the OECD Joint Working Party on Agriculture and Trade for their valuable comments and direction. 


\section{Table of contents}

$\begin{array}{ll}\text { Introduction } & 3\end{array}$

Why Chinese grain imports could increase 4

$\begin{array}{ll}\text { Scenario assumptions } & 6\end{array}$

$\begin{array}{ll}\text { Results } & 7\end{array}$

$\begin{array}{lr}\text { Conclusion } & 10\end{array}$

$\begin{array}{lr}\text { References } & 11\end{array}$

\section{Figures}

Figure 1. Chinese grain imports (left) and international grain prices (right) 3

Figure 2. Calorie imports (left) and calorie self-sufficiency rates (right) of China 5

Figure 3. Tariff Rate Quota fill rates for wheat and maize in China 6

Figure 4. Chinese imports of maize: Scenario and baseline 7

Figure 5. Absolute change of Chinese feed commodity imports compared to the baseline, $2030 \quad 8$

Figure 6. Nominal and real world maize price and FAO food price index 9

Figure 7. Relative change in food availability and expenditures: Scenario vs baseline 9

Figure 8. Absolute change in net trade values: Scenario vs baseline 10 


\section{Introduction}

International grain prices increased strongly between mid-2020 and mid-2021 (Figure 1), a surprising development for many market analysts as international grain prices had remained flat over several marketing seasons. Several factors contributed to this increase. While global stocks were high at the beginning of the 2020/2021 season, several major producing countries experienced lower harvests than anticipated. And although the overall effects of the COVID-19 pandemic on agricultural trade were fairly low, it nevertheless created logistical bottlenecks, uncertainties in the market, and temporary export restrictions in several countries (OECD, 2020[1] $)\left(\right.$ OECD, 2020[2]), (Arita et al., 2021 ${ }_{[3]}$ ). However, a more important factor behind these price hikes could be the substantial increase in grain imports by the People's Republic of China (hereafter "China") well above levels of the past (Figure 1); imports were largely driven by the gradual rebuilding of Chinese pig herds following the 2019 outbreak of African Swine Fever (ASF). In order to meet the demand for feed, the country sharply increased its imports. Other factors explaining the increase in Chinese grain imports include improved trade relations with the United States, ${ }^{1}$ stagnant domestic maize production, and high domestic prices.

Figure 1. Chinese grain imports (left) and international grain prices (right)

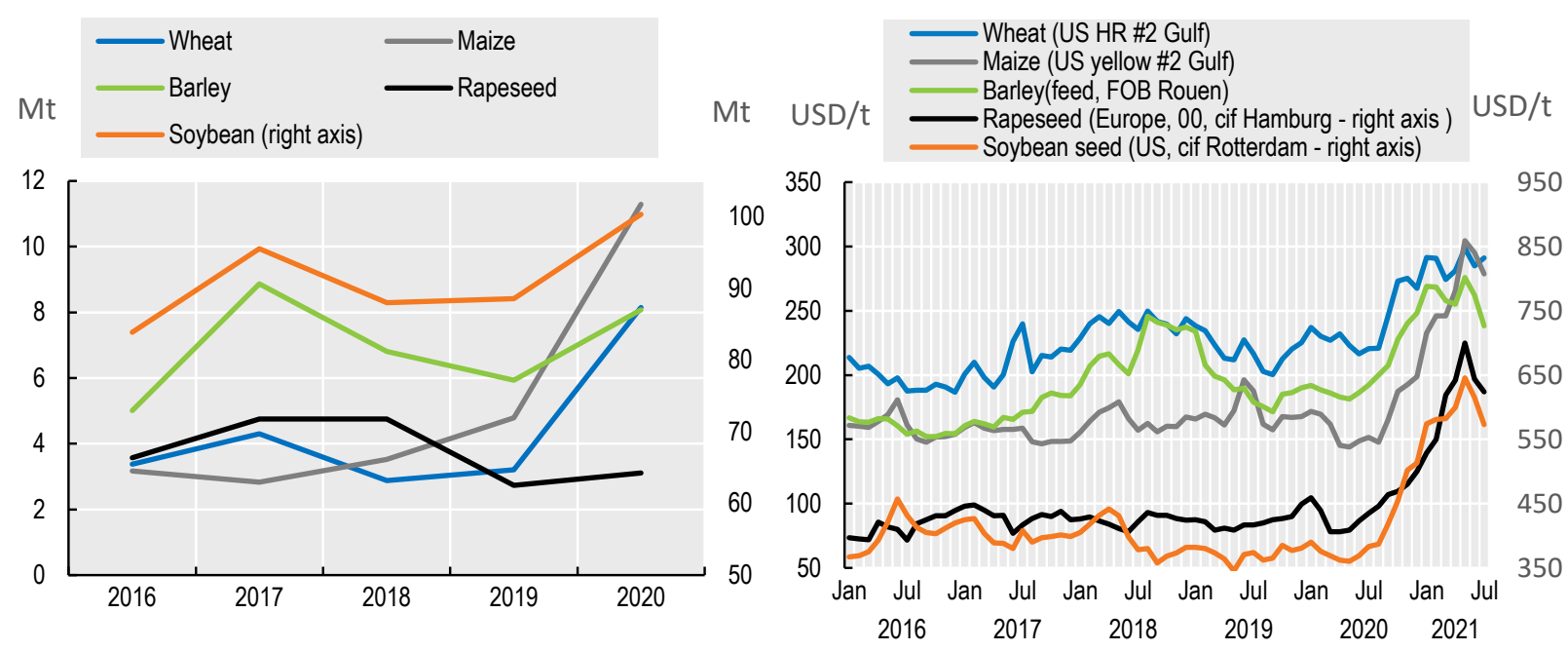

Note: Imports are in calendar years.

Source: Import data: UN Comtrade, Price data: GIEWS FPMA Tool.

\footnotetext{
${ }^{1}$ See Economic and Trade Agreement between the United States and the People's Republic of China: Phase One, 15 January 2020. Downloaded from https://ustr.gov/countries-regions/china-mongolia-taiwan/peoples-republicchina/phase-one-trade-agreement/text.
} 
The OECD-FAO Agricultural Outlook 2021-2030 (2021[4]) (hereafter the "Outlook") assumes that these large trade flows are a short-term phenomenon that will end when pig herds have been rebuilt ${ }^{2}$ (the Outlook assumes this to be by 2022/23). Over the coming decade, Chinese grain imports are projected to be higher than in the past, but considerably below 2020/2021 values. However, recent price shifts have raised public concerns that food markets may enter a new phase of high price inflation if Chinese import demand for feed grains continues to increase. This brief examines the potential impact this would have on agricultural commodity markets. It uses the baseline of the Outlook as a reference.

\section{Why Chinese grain imports could increase}

Chinese grain markets in 2020/2021 were not in a medium-term equilibrium given the global uncertainty created by the COVID-19 pandemic and the changes in the meat demand mix following the outbreak of ASF (poultry and fish substituted for a large percentage of pork demand) (Frezal, Gay and Nenert, 2021 [5]). In this situation, it is difficult to determine how much of the observed market behaviour can be attributed to short-term effects and what might result from a change in market fundamentals. A major uncertainty is whether the Chinese pork sector will become more commercialised following herd rebuilding. While some argue this might be the case, ${ }^{3}$ the impact it will have on feed demand is less clear. More commercialised production systems tend to use more tradable feed products than does backyard farming, but they might be more feed efficient. The net effect of a more rapid commercialisation of this sector on feed demand in China is, therefore, hard to predict although in the past the former effect seems to have dominated as the amount of feed used to produce one unit of pork or poultry meat has been increasing. The Outlook assumes that feed conversion will be lower than it was over the past three years for both pork and poultry, and that the trend in commercialisation, and thus of additional feed, needed per unit of produced meat will slow down.

Another source of uncertainty is whether domestic feed production can keep up with increasing demand in China. Future production growth of maize, the largest domestic feed grain source, is particularly uncertain. Since the abolition of the Minimum Support Price (MSP) for maize in 2015, production has been decreasing, although it started to increase slightly in 2019. Harvested maize areas have also been decreasing since 2015, while soybean areas have been increasing. The Outlook assumes that maize areas will recover and start to increase again. But what if this is not the case?

The uncertainty about actual stock levels also adds to the uncertainty around China's medium term feed gap. Temporary stocks piled up while the MSP system was in place, but these have since decreased by an estimated average annual increment of $10 \mathrm{Mt}$ according to the Outlook database. There is some evidence that these temporary stocks have been depleted and thus it is possible that the period of continuous additional supply from stocks could be over (Collier, Bedford and Lucarelli, 2021 [6]). However, this in turn could mean that annual maize stocks move from being a source of additional supply to a source of additional demand, ${ }^{4}$ thus potentially increasing the national net deficit in feed maize. The Outlook includes this assumption in its baseline.

\footnotetext{
${ }^{2}$ Feed demand during the period when pig herds are being rebuilt could be higher compared to an equilibrium after this period because the commodities that benefited from ASF - such as poultry or fish - will continue to be produced at a higher level than was the case before ASF. However, once a new equilibrium for meat demand in China is found, feed demand should be lower.

3 The USDA, Economic Research Service and World Agricultural Outlook Board, for example, have forecast an acceleration of commercial pork production above its previous trend as the sector's expansion gains traction.

${ }^{4}$ Because stocks held for food security reasons continue to increase in proportion to population growth.
} 
Figure 2. Calorie imports (left) and calorie self-sufficiency rates (right) of China
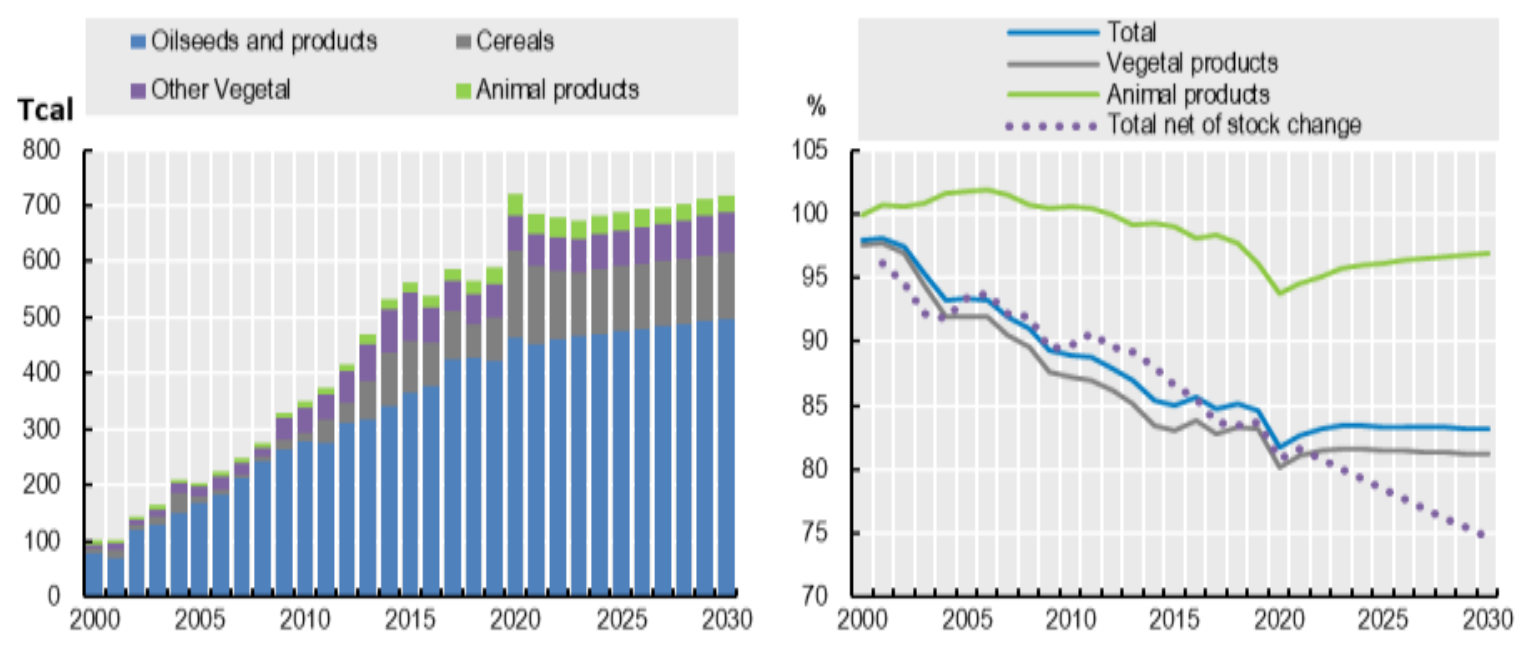

Note: Estimates only include the main products reflected in the Outlook. Animal products include fish. Self-sufficiency rates are calculated with the formula production / (production + imports - exports) in calorie equivalents. For the series Total net of maize stock change, maize stock change has been subtracted in the denominator as an additional factor.

Source: OECD/FAO (2021), "OECD-FAO Agricultural Outlook", OECD Agriculture statistics (database), http://dx.doi.org/10.1787/agr-outl-dataen.

Despite policies to ensure self-sufficiency ${ }^{5}$ (Bishwajit et al., $\left.2013_{[7]}\right)$, China's total rate of self-sufficiency for products covered in the Outlook has been decreasing since 2000 (Figure 2, right panel). This negative trend is mainly driven by increases in vegetal product imports, particularly oilseeds (Figure 2, left panel). The Outlook projects that self-sufficiency will return to the trends observed during the period 2015 to 2019. However, the trends that seem to have flattened since 2015 could be misleading as this period coincides with the destocking phase of temporary maize stocks mentioned above.

The dotted line in Figure 2 shows what self-sufficiency could have been had excess maize production during the period when the MSP system was active been exported rather than stocked, and if the additional supply from temporary stock depletion between 2015 and 2020 had been imported. This hypothetical series is particularly interesting since the MSP system was abolished as it gives a better indication of the self-sufficiency rate in the absence of additional supply from stocks, which would be the same situation as for the coming years. The dotted line does not flatten between 2015 and today, and is lower than the actual self-sufficiency series. If extended by a ten-year trend for 2021 to 2030 , self-sufficiency would decrease more than what is reflected in the Outlook. Although a simple trend analysis does not factor in economic behaviour such as the scenario analysis that follows, it might indicate that the total calorie deficit of China could continue to increase in the future.

\section{Tariff Rate Quotas}

Tariff Rate Quotas (TRQs) for cereals could be a legal barrier to further increases of Chinese grain imports. The way China has managed its TRQs for wheat, maize and rice in the past has been subject to international critique because TRQ-fill rates have been notably below $100 \%$ for wheat and maize

\footnotetext{
${ }^{5}$ Grain sufficiency has always been at the heart of China's national food security agenda, as in most other Asian countries
} 
(Figure 3). ${ }^{6}$ Deuss and Adenauer $\left(2020_{[8]}\right)$ explored this issue with different assumptions on how China would handle TRQs in the future, but data for 2019 and 2020 were not yet available and assuming TRQs to be overfilled seemed highly unlikely. Given the improved trade relations between China and the United States and China's commitment to administer TRQs more transparently in the future, it has become more likely that the TRQs will continue to be filled during the next decade. This assumption is included in the Outlook.

Is there an economic explanation as to why maize imports exceeded TRQs in the 2020/2021 marketing year? It is highly unlikely that these imports were subject to the out quota tariffs as this would render trade flows very unattractive for exporters. One explanation could be that China might be importing grains for stocks, which are not subject to TRQs (Collier, Bedford and Lucarelli, 2021 $\left.{ }_{[6]}\right]$. If true, this would confirm that temporary stocks are currently depleted.

Figure 3. Tariff Rate Quota fill rates for wheat and maize in China

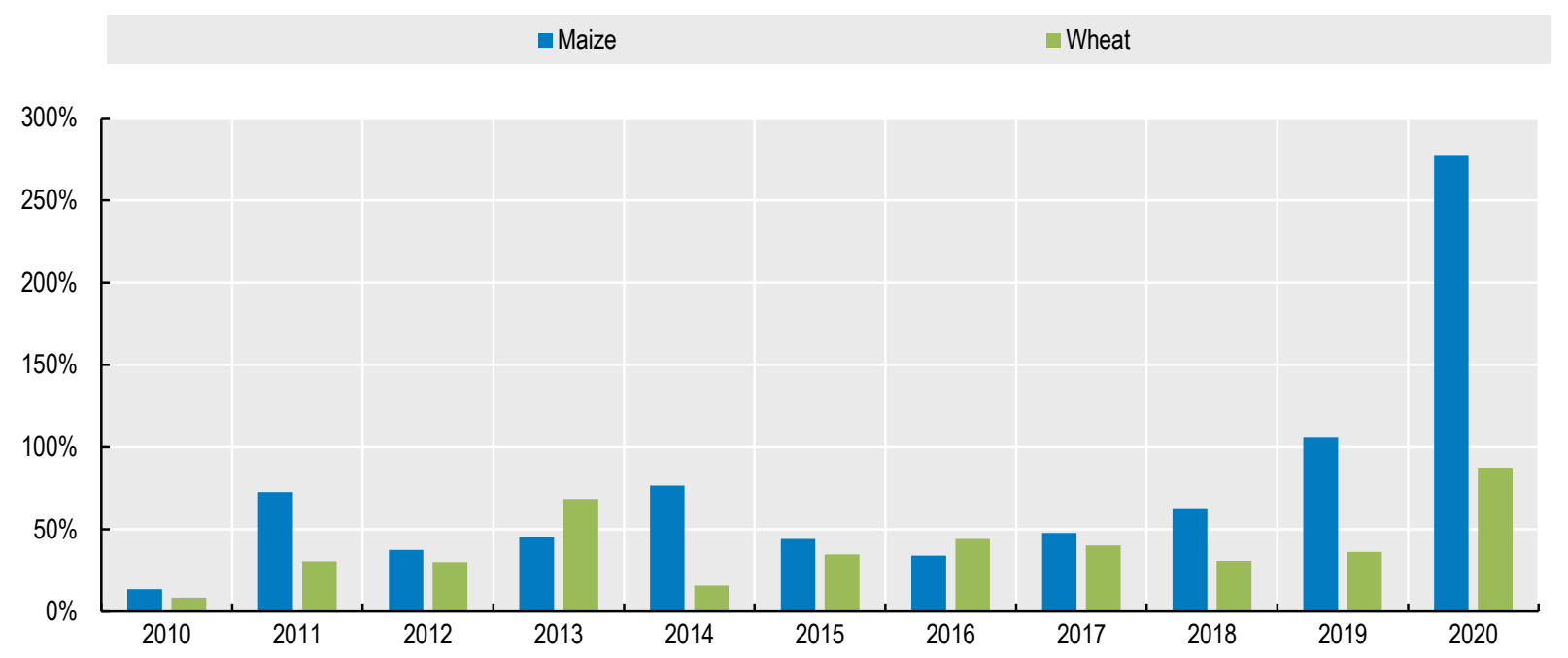

Source: OECD/FAO (2021), "OECD-FAO Agricultural Outlook”, OECD Agriculture statistics (database), http://dx.doi.org/10.1787/agr-outl-dataen.

\section{Scenario assumptions}

On the basis of these considerations, OECD developed an "extreme Chinese feed deficit" scenario using the Aglink-Cosimo model. In this scenario, the feed deficit in China increases strongly over the next ten years based on the following assumptions:

- The speed of conversion from backyard to commercial farming stays on trend in the pork and poultry sectors, thereby increasing the amount of bulk feed needed to produce one unit of pig or poultry meat.

\footnotetext{
${ }^{6}$ Fill rates were also below $100 \%$ for rice, but since this analysis focusses on feed commodities, rice is not taken into account here.
} 
- Harvested areas of maize in China continue to decrease, following recent trends assuming that area difference to the Outlook is not available. ${ }^{7}$

- Yield growth for cereals and oilseeds slows down compared to the Outlook baseline. ${ }^{8}$

- $\quad T R Q s$ for wheat and maize would not be active because the scenario mimics a situation where China cannot satisfy domestic feed demand with domestic production, and in such a situation it would be in the country's interest not to apply the out-quota tariffs.

\section{Results}

\section{Chinese imports of all feeds increase}

In this scenario, Chinese maize imports increase to almost $37 \mathrm{Mt}$ in 2030, $30 \mathrm{Mt}$ more than under the Outlook baseline (Figure 4). China becomes by far the largest importer of maize, accounting for $15 \%$ of global maize imports. The volumes of maize that are traded internationally increase by more than $10 \%$ relative to the baseline.

\section{Figure 4. Chinese imports of maize: Scenario and baseline}

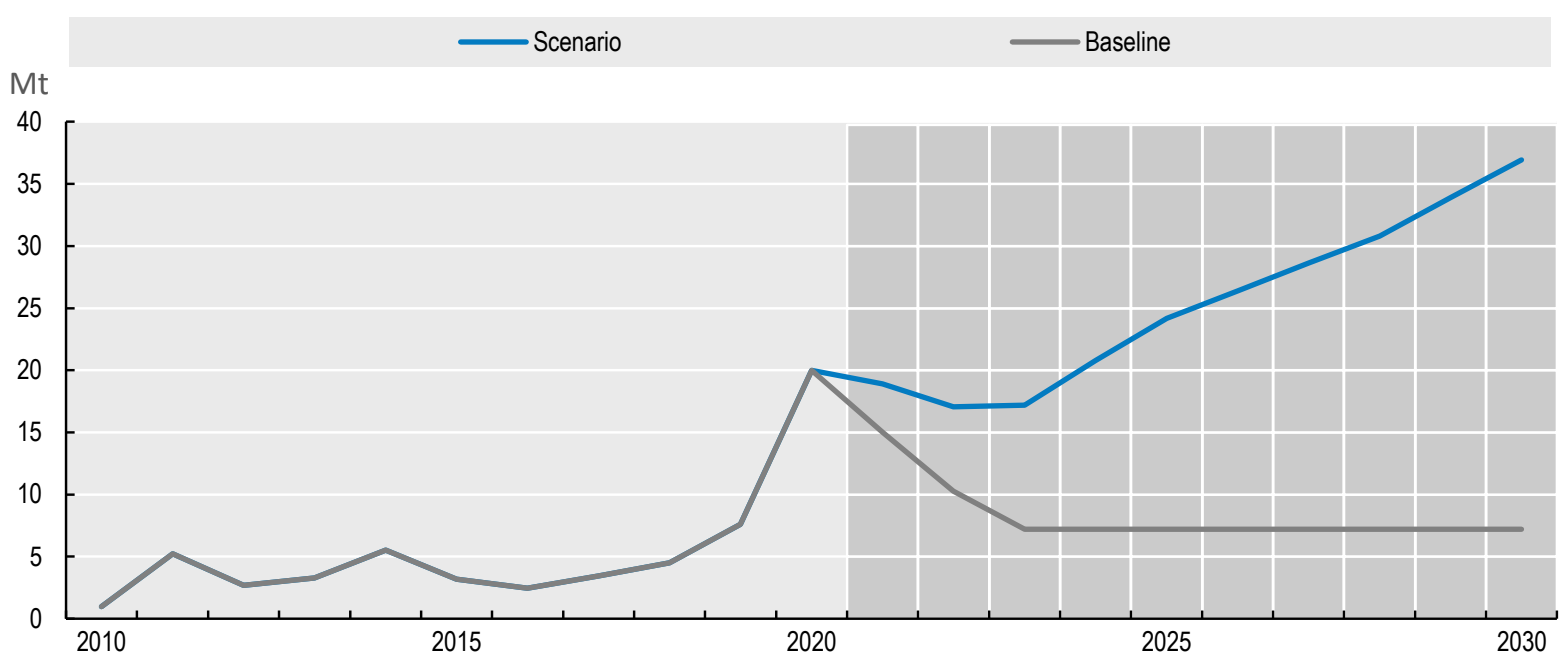

Source: Aglink-Cosimo simulations.

\footnotetext{
${ }^{7}$ Area restrictions might also become tighter in the future than what is assumed in the Outlook, with pressure coming from crops not modelled in Aglink-Cosimo or from other land uses. This scenario only assumes changes to maize areas as maize is the only cereal where the Outlook assumes future increases despite recent declining trends.

${ }^{8}$ Yield growth is a major driver of the Outlook projections. While this growth is based on historical trends as well as other considerations such as climate change or input availability, it is an uncertain variable. This scenario uses a more pessimistic assumption on yield growth of feed commodities in China than does the Outlook.
} 
As seen in Figure 5, maize is the commodity most affected under this scenario. There are two reasons for this. First, it is the largest primary feed commodity in China, with a share in total feed use of over $20 \%{ }^{9}$ Second, it is the only commodity which is directly impacted by all scenario parameters (i.e. feed conversion effect, maize area effect, and yield effect). The scenario results also show that imports of other feed commodities increase notably in absolute terms as well as in relative terms for most commodities. The exception is soybeans, which start from already large import quantities (Figure 1) but a less pronounced relative increase.

Figure 5 shows a breakdown of the scenario results by the three different types of shocks that were implemented. The scenario assumptions on feed conversion rates are the most important factor for all commodities. The assumptions on maize areas mainly affect maize with smaller spill over effects on other crops, while the yield impact is notably lower than the feed conversion effect.

Figure 5. Absolute change of Chinese feed commodity imports compared to the baseline, 2030

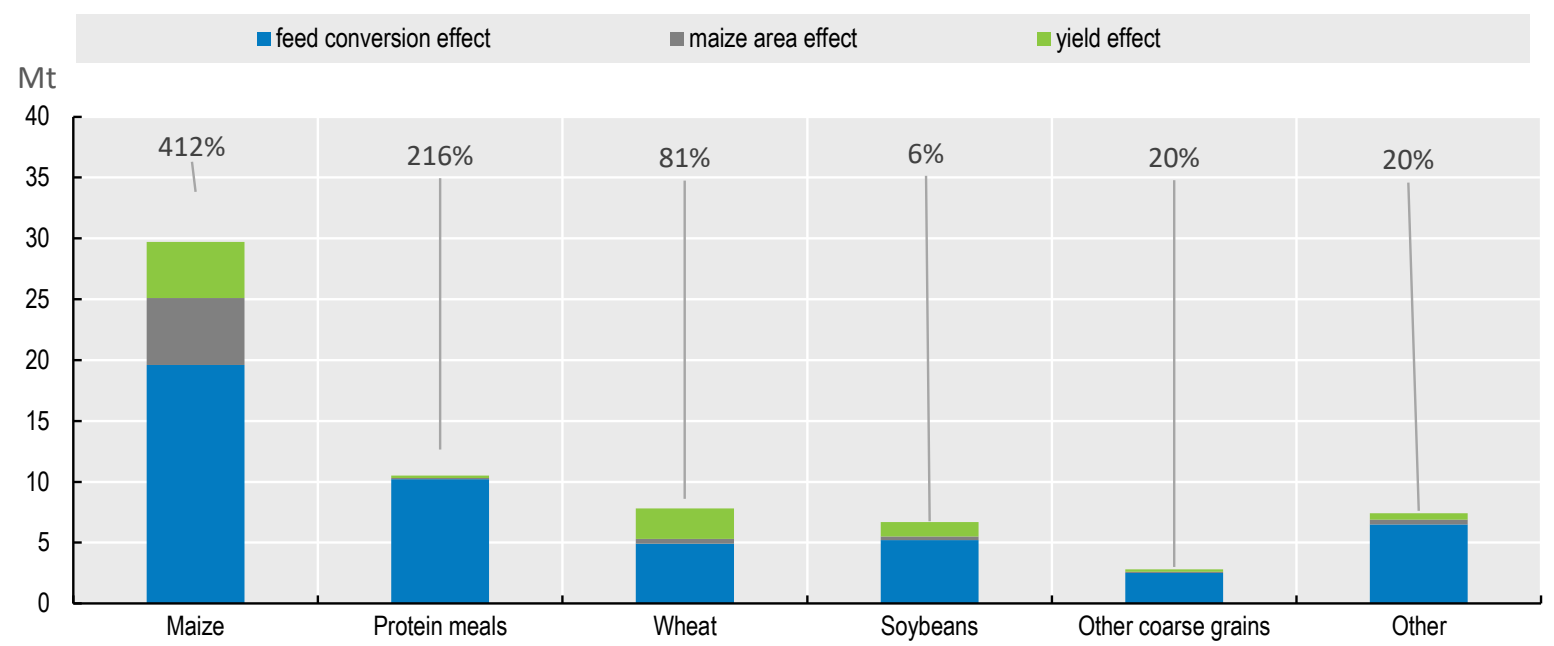

Source: Aglink-Cosimo simulations.

\section{Agricultural commodities become more expensive, threatening food security for poor population}

As expected, the additional feed demand in the scenario drives up food price inflation. Figure 6 shows the evolution of the world maize price and of the FAO food price index. In 2030, maize prices in the scenario would be about USD 30/t (14\%) higher than in the Outlook baseline. In general, agricultural commodity prices would be between $4 \%$ to $25 \%$ higher than in the baseline, which would translate into a 7 percentage point increase in the FAO Food Price Index compared to the baseline level.

\footnotetext{
${ }^{9}$ Only protein meals have a larger share; but since protein meal is a processed product, the effect is mitigated across meals and oilseeds.
} 
Figure 6. Nominal and real world maize price and FAO food price index
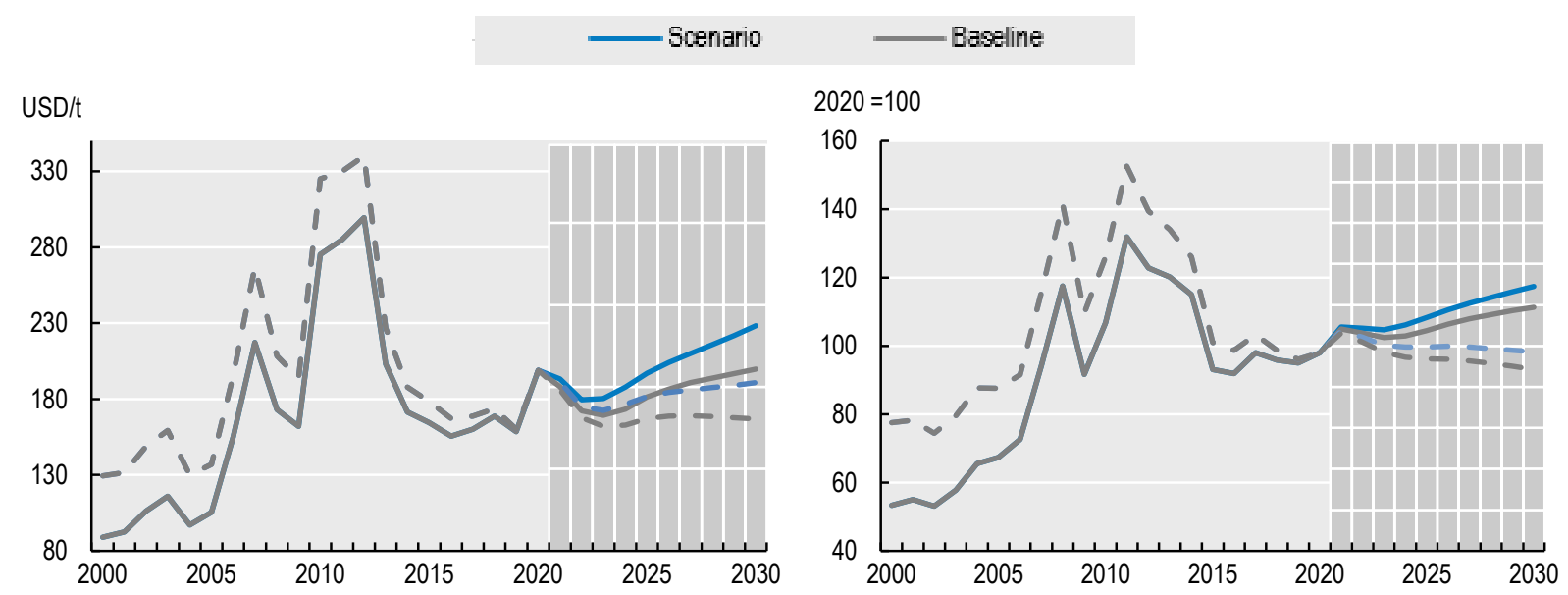

Notes: Dashed series are real prices.

Source: Aglink-Cosimo simulations.

Despite the limited increase in food prices relative to the Outlook baseline, higher prices would increase the risk of food insecurity. Figure 7 shows that the impact on food expenditures is strongest for China because domestic prices increase the most compared to other countries. However, countries that belong to country groups with low and lower-middle incomes face increased food expenditures as well as small decreases in food availability results in food becoming more expensive. Although the decrease in average daily food availability is low, it could be much higher for the poorest segments of the population given the disparate impact of increased prices.

Figure 7. Relative change in food availability and expenditures: Scenario vs baseline

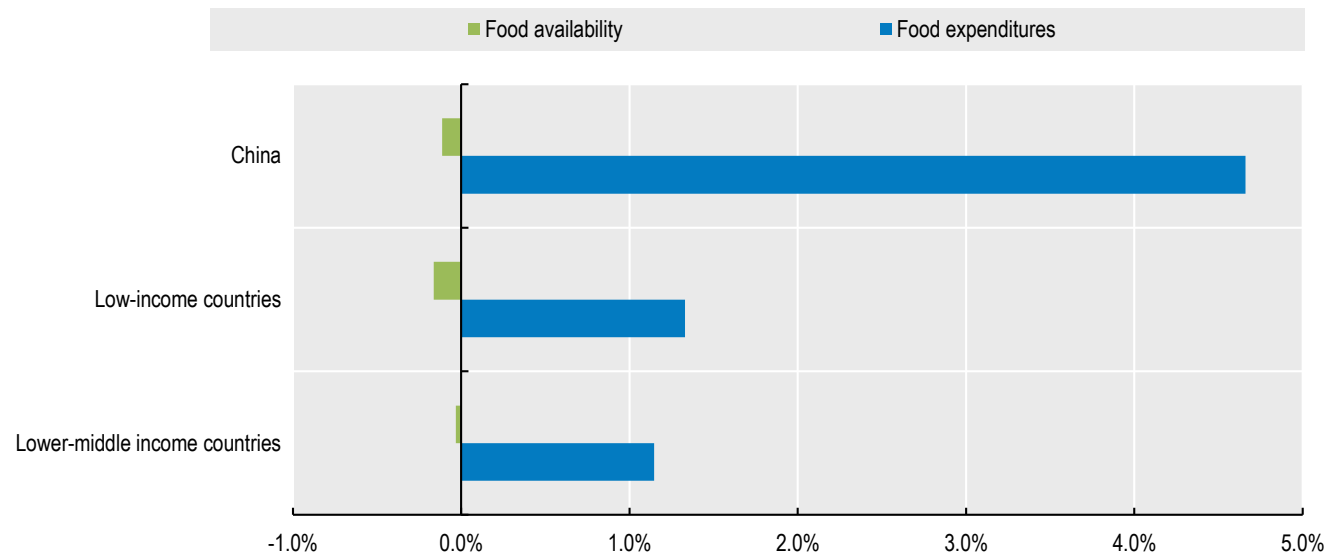

Source: Aglink-Cosimo simulations. 


\section{Some countries gain, others lose}

In this scenario, the additional import demand of China benefits exporting countries. Grain-exporting countries increase their trade bill. Figure 8 shows the change in trade values (export values minus import values) for countries that are the most affected in this analysis. Conversely, China is at the top, as its imports increase significantly under this scenario due to the scenario assumptions. Other importdependant countries also show negative changes in their trade values as global commodity prices, and thus import prices, are higher.

Figure 8. Absolute change in net trade values: Scenario vs baseline

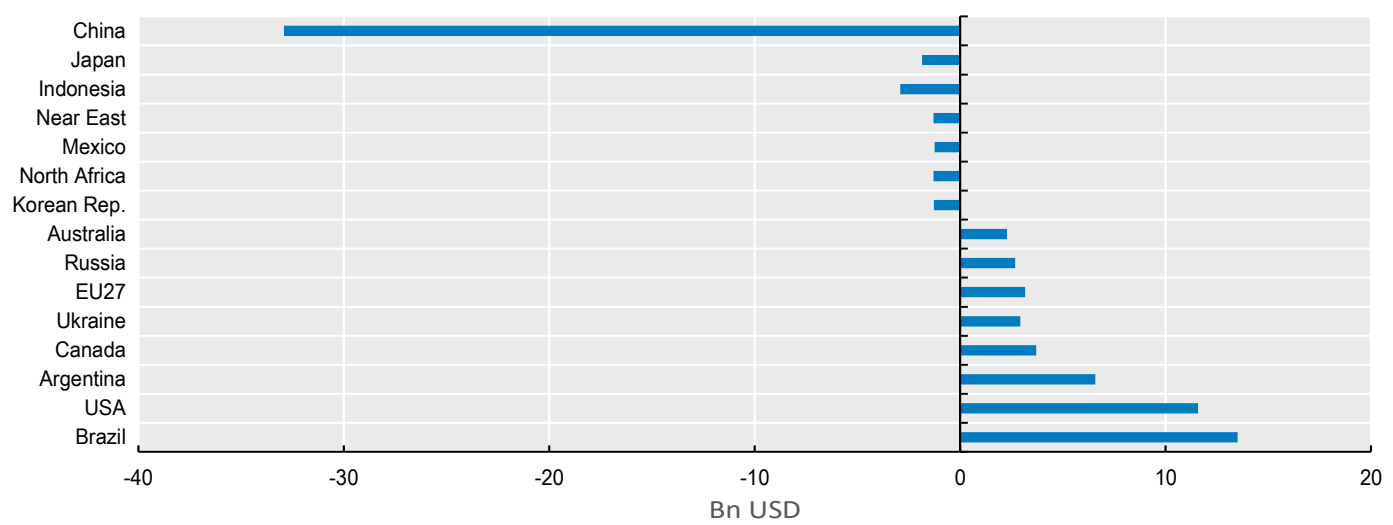

Note: Trade values include only commodities captured in the Outlook database and are calculated as net trade times world market prices. Source: Aglink-Cosimo simulations.

\section{Conclusion}

Increased Chinese grain imports during the 2020/2021 marketing season have disrupted international grain markets. Although most market fundamentals point towards a slowdown in the coming years, there is a possibility that China's net feed deficit will continue to increase over the next decade. This analysis finds that in a situation where China imports more than $15 \%$ of global maize trade, agricultural commodity prices could be between $4 \%$ to $25 \%$ higher compared to the OECD-FAO Agricultural Outlook 2021-2030 projections. This would improve the prospects for feed-exporting countries, but increase the risk of food insecurity for the poorest segments of the global population. 


\section{References}

Arita, S. et al. (2021), Has Global Agricultural Trade Been Resilient Under Coronavirus

[3] (COVID-19)? Findings from an Econometric Assessment., Food Policy (forthcoming).

Bishwajit, G. et al. (2013), "Self-sufficiency in rice and food security: a South Asian perspective”, Agriculture \& Food Security, Vol. 2/1, http://dx.doi.org/10.1186/2048-7010-2$\underline{10 .}$

Collier, E., D. Bedford and L. Lucarelli (2021), China and the Global Short Term Grain Market Outlook., Presentation at the IATRC-summer symposium 2021., https://iatrc.umn.edu/2021-iatrc-oecd-symposium/.

Deuss, A. and M. Adenauer (2020), "China's grain reserves, price support and import policies: Examining the medium-term market impacts of alternative policy scenarios", OECD Food, Agriculture and Fisheries Papers, No. 138, OECD Publishing, Paris, https://dx.doi.org/10.1787/f813ed01-en.

Frezal, C., S. Gay and C. Nenert (2021), "The Impact of the African Swine Fever outbreak in China on global agricultural markets", OECD Food, Agriculture and Fisheries Papers, No. 156, OECD Publishing, Paris, https://dx.doi.org/10.1787/96d0410d-en.

OECD (2020), Food Supply Chains and COVID-19: Impacts and Policy Lessons, accessible at https://www.oecd.org/coronavirus/policy-responses/food-supply-chains-and-covid-19impacts-and-policy-lessons-71b57aea/.

OECD (2020), The role of transparency in avoiding a COVID-19 induced food crisis, accessible at https://www.oecd.org/coronavirus/policy-responses/the-role-of-transparencyin-avoiding-a-covid-19-induced-food-crisis-d6a37aeb/.

OECD/FAO (2021), "OECD-FAO Agricultural Outlook 2021-2030", in OECD-FAO Agricultural Outlook 2021-2030. 


\section{OECD FOOD, AGRICULTURE AND FISHERIES PAPERS}

This report was prepared for publication by the OECD Secretariat.

This report, as well as any data and any map included herein, are without prejudice to the status of or sovereignty over any territory, to the delimitation of international frontiers and boundaries and to the name of any territory, city or area.

Comments are welcome and can be sent to tad.contact@oecd.org. 